\title{
El historicismo como conciencia de una ruptura: la formulación dialéctica de Rodolfo Agoglia en la filosofía latinoamericana del siglo XX
}

Historicism as an awareness of a rupture: Rodolfo Agoglia's dialectical formulation in 20th-century Latin American philosophy

O historicismo como consciência de uma ruptura: a formulação dialética de Rodolfo Agoglia na filosofia latinoamericana do século XX

Noelia Liz Gatica*

\section{RESUMEN}

Mediante la ampliación metodológica de la Historia de las Ideas (Roig), nos enfocamos en una vertiente del historicismo latinoamericano que emerge en el seno de las universidades argentinas y que, según entendemos, puede ser rastreada en la producción filosófica de Rodolfo Agoglia (1920-1985). Dado que los principales estudios sobre el historicismo latinoamericano ligados al proceso de institucionalización de la Historia de las Ideas identifican al menos tres momentos significativos (emergencia, crisis y reformulación metodológica) y establecen diferencias teóricas entre las formulaciones iniciadas en México y en Argentina, apuntamos a dar cuenta del contexto en el que Agoglia desarrolla sus primeras reflexiones sobre el historicismo romántico. Posteriormente avanzamos en la caracterización de su formulación madura definida como "conciencia de una ruptura".
Palabras

clave: filosofía

latinoamericana, historicismo latinoamericano, filosofía argentina, historicidad

Argentina. Doctora en Filosofía. Universidad Nacional de Cuyo. Becaria Posdoctoral del INCIHUSA-CCT, CONICET, Argentina. Contacto: ngatica@mendoza-conicet.gob.ar ORCID: https://orcid.org/0000-0002-8777-461X 


\section{SUMMARY}

Through the methodological extension of the History of Ideas (Roig), we focus on Latin American historicism that emerges within Argentine universities, traced in the philosophical production of Rodolfo Agoglia (1920-1985). Significant studies on Latin American historicism linked to the History of Ideas' institutionalization identify at least three significant moments- emergence, crisis, and methodological reformulation. It also establishes theoretical differences between the formulations initiated in Mexico and Argentina. We aim to give an account of the context in which Agoglia develops his first reflections on Romantic historicism. Later on, we advanced in its mature formulation's characterization defined as "awareness of a rupture."

\section{RESUMO}

Através da ampliação metodológica da História das Ideias (Roig), concentramo-nos em uma vertente do historicismo latino-americano que emerge no coração das universidades argentinas e que, segundo nosso entendimento, pode ser rastreada na produção filosófica de Rodolfo Agoglia (1920-1985). Uma vez que os principais estudos sobre o historicismo latino-americano vinculados ao processo de institucionalização da História das Ideias identificam ao menos três momentos significativos (emergência, crise e reformulação metodológica) e estabelecem diferenças teóricas entre as formulações iniciadas no México e na Argentina, nosso objetivo é apresentar o contexto em que Agoglia desenvolve suas primeiras reflexões sobre o historicismo romântico. Posteriormente avançamos na caracterização de sua formulação madura, definida como "consciência de uma ruptura".
Keywords: Latin American philosophy, Latin American historicism, Argentine philosophy, historicity

Palavras-chave: filosofia latinoamericana, historicismo latino-americano, filosofia argentina, historicidade 


\section{Introducción}

Las herramientas metodológicas procedentes del historicismo latinoamericano contribuyen en el proceso de institucionalización de la Historia de las Ideas (Roig 1993; Arpini 2003; Pérez Zavala 2005). A diferencia del historicismo europeo, las expresiones historicistas latinoamericanas reconocen sus antecedentes en la generación romántica del siglo XIX, los años 40 como momento de emergencia, su crisis en el contexto de las teorías de la dependencia y un posterior periodo de reformulación o "ampliación" metodológica a partir de la discusión sobre el problema de las ideologías (Arpini 2003).

En alusión al desarrollo del historicismo en Argentina, Arturo Roig (1993) señala que, si bien el interés por recuperar nuestras ideas se manifiesta a mediados del siglo XIX, adquiere relevancia en la primera década del siglo XX, con las investigaciones de Alejandro Korn (1912), José Ingenieros (1914) y Emilio Ravignani (1916). A fines de los años 20, por iniciativa de Coriolano Alberini, se crea el Instituto de Filosofía de la Facultad de Filosofía y Letras de la Universidad de Buenos Aires que, "entre otros objetivos, tenía el de la 'publicación de documentos para la historia del pensamiento argentino en su aspecto filosófico"' (Roig 1993 93). En la década del 30, los estudios de Alberini La filosofía alemana en la Argentina (1930) y "La metafísica de Alberdi" (1934), junto con la publicación de la versión definitiva de Influencias filosóficas en la evolución nacional (1936), de Alejandro Korn, inician al menos dos líneas de investigación que establecen diferencias no solo teóricas, sino también políticas con la llegada del peronismo.

Francisco Romero $(1944,1953)$ continúa la investigación de Korn desde una perspectiva culturalista, que distingue entre el orden lógico del pensamiento y sus repercusiones. En el plano sociocultural, "las ideas ya no valen desde un punto de vista teórico, sino vital y se integran en las Weltanschauungen diltheyanas" (Roig 1993 96). Roig afirma que las categorías historiográficas de Alberini, metodológicamente marcadas por "la atmósfera biologicista de la época", son reformuladas desde el existencialismo y la fenomenología por Luis Juan Guerrero (1945) y Carlos Astrada (1948, 1968). Discípulo de Alberini, Guerrero y Astrada, Rodolfo Agoglia (1920-1985) configura en los 50 un historicismo dialéctico, que no solo se apropia de las formulaciones románticas teóricas europeas y latinoamericanas, sino que, durante los 70, asume 
el compromiso con la transformación de la realidad histórica, explicitada en su alusión a la reivindicación de la identidad nacional y la necesidad de lograr una efectiva liberación.

Por una parte, el historicismo latinoamericano ha sido estudiado en vinculación con el proceso de institucionalización de la historia de las ideas (Arpini 2003). Formulado en el seno de las universidades e institutos de investigación latinoamericanos en la década del 40, el historicismo es empleado como herramienta metodológica en un determinado universo discursivo, no ajeno a las prácticas académicas caracterizadas por el ambiente de "normalización". Tanto Roig como Arpini señalan que las discusiones del historicismo no estuvieron exentas de las limitaciones del academicismo. A fines de los 60, en el contexto de las teorías de la dependencia y la teoría crítica de las ideologías, advierten un momento de crisis del historicismo, que guarda relación con el paradigma normalizador y que incide posteriormente en un periodo de reformulación de las herramientas metodológicas para el estudio de nuestras ideas.

Este escenario también ha sido estudiado por Horacio Cerutti (2006) en relación con el momento de emergencia de las filosofías de la liberación. La discusión sobre la existencia, forma y función de la filosofía latinoamericana es asumida por el movimiento liberacionista, que ya en la publicación de Hacia una filosofía de la liberación latinoamericana (1973) patentiza la heterogeneidad teórica, metodológica y política del movimiento. El pensador mendocino, radicado en México, desarrolla la polémica en torno a la discusión entre historicistas y populistas respecto de las nociones de "pueblo" y "lo popular". Sumado a esto, en un escrito reciente, Cristóbal Friz Echeverría (2019) introduce dos variables que tensionan el debate protagonizado por Salazar Bondy y Leopoldo Zea a fines de los 60 (Fritz 2019). El contexto de profesionalización de la filosofía junto con los límites y alcances de la "normalidad filosófica", por una parte, y la alusión a la "sensibilidad setentista" en los términos del compromiso, por otra, estructuran los tópicos centrales en el célebre debate: la pregunta por la tradición de la filosofía latinoamericana (su reconocimiento o negación), la disyuntiva sobre la forma y los desplazamientos categoriales de Zea respecto de la pregunta de Salazar.

En nuestra investigación nos proponemos advertir el modo en que las formulaciones del historicismo en Rodolfo Agoglia pueden 
ser analizadas en el contexto de la institucionalización de la Historia de las Ideas, como disciplina, y en relación con las ideas liberacionistas desarrolladas en la década de los 70. Avanzamos en una localización de la producción discursiva del pensador argentino dentro de una línea de investigación de la Historia de las Ideas que difiere teórica y políticamente de la de Francisco Romero, y que desarrolla su producción teórica madura entre el contexto de transformación de las universidades argentinas que dará lugar a la Ley Orgánica de Universidades 20.654 y su exilio en Ecuador. Guiados por las precauciones metodológicas de Arturo Roig, atendemos a los textos en relación con los contextos, y comprendemos los discursos como reformulaciones de la conflictividad social. Desde la Historia de las Ideas latinoamericana y en sintonía con Hugo Biagini (2015), apuntamos a no olvidar su "objeto básico de estudio: el ser humano y su conflictividad social" (Biagini 2015 12). De este modo, realizamos un abordaje epistemológico que pretende dar cuenta de la historicidad de las ideas, evitando reducir la investigación a la mera descripción del "andamiaje conceptual", desde el rescate de la complejidad histórica en que se urden las ideas. Prestamos atención a los diversos movimientos de alusión, elusión e ilusión discursiva ${ }^{1}$ que estructuran los textos de Agoglia y, mediante un intento de reconstrucción histórica del contexto filosófico universitario argentino, damos cuenta del modo en que su propuesta se inserta en el universo discursivo del historicismo latinoamericano. Su crítica a la especialización y al formalismo, así como su distanciamiento respecto de las ciencias del espíritu, nos permiten trazar un recorrido singular contemporáneo a los desarrollos del historicismo en América Latina. Sumado a esto y en segundo

1 Arturo Roig propone un abordaje epistemológico de los materiales de investigación de la Historia de las Ideas que contemple el contexto de emergencia histórica de los discursos. De este modo, un "universo discursivo, incluye, como es fácil pensarlo, formas discursivas diversas que adquieren su pleno sentido, por lo demás, de la totalidad discursiva dentro de la cual se encuentran insertas. (...) No hay solo un discurso (aun cuando haya formas dominantes) es lo que se podría afirmar desde el principio de la 'diversidad discursiva,', no hay paz a nivel discursivo, como no la hay a nivel social. Hay, por lo tanto, lo que hemos llamado 'discursos' y 'discursos contrarios'. Y, por último, cierta línea discursiva (...) muestra un modo específico de referencialidad discursiva. Esto lo decimos a propósito del modo como en esa línea se organiza el 'sistema de discursos referidos' - Voloshinov tiene la palabra en esto-, es decir, de qué manera se lleva a cabo la asimilación del anti-discurso, de qué modo se lo elude y se lo incluye del ámbito del propio discurso, etc." (Roig 2013 246-247). 
lugar, tomamos relativa distancia de las categorías historiográficas, con el fin de explicitar el modo en que se configura la singularidad de su propuesta, caracterizada no solo por el contexto en que tiene lugar su producción discursiva, sino también por su posición teórica y política caracterizada como conciencia de una ruptura.

\section{Emergencia del historicismo latinoamericano: los años 40 y la relectura del Romanticismo}

Adriana Arpini (2003) y Pérez Zavala (2005) coinciden en afirmar que la actualización de los problemas teóricos procedentes del Romanticismo del siglo XIX, propician las discusiones teóricas del historicismo contemporáneo europeo y latinoamericano. La pensadora mendocina describe cuatro etapas dentro del historicismo europeo: la expresión prehistoricista romántica y su reelaboración por Wilhelm Dilthey, la formulación subjetivista de Ernst Troeltsch y la configuración madura del historicismo de Bernard Groethuysen. En cuanto al historicismo latinoamericano, sostiene que José Gaos y Francisco Romero, a partir de las lecturas de Wilhelm Dilthey y José Ortega y Gasset, emprenden, en la década de los 40, una labor de reconstrucción del pensamiento latinoamericano orientada por las ideas románticas del siglo XIX.

En relación con la emergencia del historicismo latinoamericano en la década del 40, Horacio Cerutti (1986), Arturo Roig (1993), Adriana Arpini (2003) y Pérez Zavala (2005), entre otros, concuerdan en indicar que el proceso iniciado fundamentalmente en los centros académicos en México, Ecuador y Argentina es contemporáneo a la culminación del proceso denominado por Francisco Romero de "normalización filosófica". No obstante:

La influencia del perspectivismo y del circunstancialismo de José Ortega y Gasset, quien a través de la Revista de Occidente difundió además la filosofía alemana de la época, Spengler, Dilthey, Scheler y otros, se hizo sentir en todo el Continente. Más tarde, la labor intelectual de José Gaos consolidó en México la influencia orteguiana. (...) En el Río de la Plata y más particularmente en la Argentina, el orteguismo no influirá tanto con su doctrina de la circunstancia, como con su teoría de las generaciones que aún en nuestros días es cultivada como método historiográfico, fenómeno visible asimismo en el Brasil (...) (Roig 1981 83). 
En 1938 José Gaos, discípulo de Ortega y Gasset, al exiliarse en México, emprende también un distanciamiento teórico respecto de su maestro. Encara las primeras traducciones al español de la obra de Dilthey, figura que es leída en alemán en las instituciones universitarias de la primera mitad del siglo $\mathrm{XX}$, "en medio de la crisis del idealismo y del fortalecimiento de las ciencias de la naturaleza" (Arpini 2003 20). Según Pérez Zavala, el historicismo diltheyano canaliza en dos corrientes en América Latina: el positivismo de los años 20 (que defiende la neutralidad valorativa y la legitimidad de los documentos canónicos) y el relativismo histórico en sus dos vertientes: una que concibe a los fenómenos culturales como históricamente determinados (naturalista), y otra que rescata la historicidad de estos (culturalista).

En el contexto de normalización de la filosofía e institucionalización de la Historia de las Ideas, Arturo Ardao (1912-2003) afirma que “(...) La crisis de la cultura occidental excita vivamente a la inteligencia de América y la mueve a la reflexión en los planos de la universalidad filosófica. (...)" (Ardao 1963 63). Pero si, por una parte, la crisis motiva la búsqueda de la personalidad espiritual en el legado de las ideas románticas de Alberdi, el "renacimiento" del historicismo coincide, al promediar el siglo XX, con la necesidad de afirmación identitaria, ideológicamente negada por el afán de verdad universal que legitiman los voceros del "colonialismo intelectual". La producción filosófica universitaria se enfrenta a los problemas procedentes de la distinción entre saber teórico y saber vital.

Francisco Romero (1940) distingue entre la formación en instituciones universitarias especializadas y la actividad autodidacta de los "fundadores". Además, destaca la tendencia creciente a estudiar las ideas filosóficas producidas en América Latina como signo de madurez de conciencia. Contemporáneo a Romero, Coriolano Alberini modula un "espiritualismo biologicista" que, desarrollado en "Introducción a la axiogenia" (1921), opera en "La metafísica de Alberdi" (1934), fundamentalmente cuando refiere al origen psicogenético de las ideas que surgen de lo orgánico como "funciones vitales", pero pueden llegar al nivel lógico del pensamiento puro (Roig 1968). Por su parte, Rodolfo Agoglia (1963), desde una "lectura hegeliana", resalta los conceptos románticos de Alberini, al focalizar en la investigación sobre Alberdi y 
la injerencia de la filosofía en la formación de la conciencia nacional (Oviedo 80).

En lo que refiere a este primer momento de "institucionalización" de la Historia de las Ideas en Argentina, más allá de las diferencias entre la interpretaciones de Roig y Agoglia, lo cierto es que: "Tanto Alberini como Romero, con su defensa de un saber 'estricto', aun cuando a su lado se reconocía ese otro nivel en el que las ideas se alejaban del logos, generaron una línea academicista de historiografía - con todos los vicios que el academicismo supone (...)" (Roig 1993 96). En el proceso de "profesionalización" de la praxis filosófica en la cultura universitaria argentina de las primeras décadas del siglo XX, se tiende a "volcar el saber especializado a la función histórico-práctica que demandaba la formación de una conciencia nacional" (Oviedo 2005 79), desde "una suerte de patriotismo aristocrático del espíritu que creían propio del proceso de profesionalización de la cultura que impulsaban" (Ibid.).

En consonancia con Roig, en el desarrollo de las primeras décadas del siglo XX se produce el proceso de institucionalización de la filosofía, con la profesionalización de la actividad académica en los centros universitarios. En las décadas siguientes (30 y 40) se inicia el proceso de institucionalización de la Historia de las Ideas. De modo que, si Ingenieros y Korn fueron los "fundadores" de la filosofía universitaria, Alberini y Romero pueden ser caracterizados como los "fundadores" de la Historia de las Ideas (Roig 1981, 1993).

Sobre el contexto de institucionalización de la Historia de las Ideas, Arturo Ardao afirma que: "América se descubre a sí misma como objeto filosófico. Se descubre en la realidad concreta de su historia y de su cultura, y aun en su naturaleza física en cuanto sostén, contorno y condición de su espiritualidad" (Ardao 68). En relación con la búsqueda de los rasgos característicos de la identidad cultural, el diálogo con la generación romántica del 37 destaca "la exaltación de lo concreto e individual, el relieve de los particularismos sociales en el espacio y en el tiempo, [y] la valoración de la experiencia histórica en su originalidad irrepetible" (Ardao 1963 67). Años más tarde Arturo Andrés Roig ensaya una lectura de Ideas para presidir a la confección del curso de filosofía contemporánea, de Juan Bautista Alberdi, en la que retoma la reflexión de un sujeto que se asume así mismo y a su tiempo como 
"posibilidad de resistencia, emergencia y transformación" (Pérez Zavala 2005 41).

Hacia la realización del I Congreso Nacional de Filosofía en 1949 se produce una ruptura entre los filósofos laicos a causa del fenómeno peronista (Velarde 2011). Existencialistas por un lado y fenomenólogos por otro, ponen en discusión la actualidad del principio reformista de autonomía universitaria, dejando al descubierto los límites del academicismo. En este contexto tienen lugar las relecturas de la generación romántica argentina, continuadas por Luis Juan Guerrero, Carlos Astrada y Rodolfo Agoglia quienes, entre otros pensadores, reivindican la importancia política de la cultura nacional ${ }^{2}$. Al respecto, Oviedo (2005) reconoce el legado de Juan Bautista Alberdi en el "espíritu politicista de orientación de una praxis nacional utópicamente motivada" en Tres temas de filosofía en las entrañas del Facundo (1945), de Luis Juan Guerrero, y en Mito gaucho (1948), de Carlos Astrada (Oviedo 94).

En los 50 Rodolfo Agoglia (1920-1985) desarrolla sus primeras reflexiones en torno a un historicismo que asume no solo las formulaciones románticas teóricas europeas y latinoamericanas, sino también el compromiso con la transformación de la realidad histórica explicitada en la alusión a la reivindicación de la identidad nacional y la necesidad de lograr una efectiva liberación. Procura tomar distancia de los vicios de la "normalización" y en el exilio recuerda que, en las cátedras de Epistemología de las universidades argentinas,

(...) incluso hasta promediar la década del sesenta, (...) se establecía una diferencia tan categórica y tajante entre las Ciencias de la Naturaleza y las Ciencias denominadas del Espíritu, que casi sin quererlo, identificábamos íntimamente a estas últimas con el Espiritismo, y nos imaginábamos la labor de estas ciencias como la ceremonia que un grupo de personas practicaba alrededor de una mesa invocando el espíritu de algunos de sus antepasados. Esta

2 Si bien, Coriolano Alberini impulsó el estudio de las ideas argentinas en el ámbito universitario y trabajó en la creación de instituciones dedicadas al pensamiento argentino, su posición teórica está atravesada por los límites del academicismo. En el discurso "La patria en la universidad" (1941), siendo Rector interino de la Universidad de Buenos Aires, alude a la distinción entre el lenguaje lógico de la ciencia y el lenguaje de las "masas" o de los "niños", a la universidad como "el hogar de la cultura especulativa y técnica" "serena casa de la ciencia, sólo habitada por profesores y alumnos dignos de serlo, (...) ajena, en consecuencia, a toda dogmática bravía o vacuo diletantismo" (Alberini 194122 ). 
identificación de las Ciencias del Espíritu con algo así como las Ciencias Ocultas, que hoy puede parecer risueña, no era más que el traslado que subconscientemente hacíamos de un planteo teórico nada convincente, que sospechábamos de academicista, a todas luces equívoco e inconsistente, pero frente al cual no se disponía por entonces de elementos científicos contrastantes, ni disuasivos, capaces de aventarlo (Agoglia, domingo 6 de marzo de 1983).

En su labor como decano de la Facultad de Humanidades y Ciencias de la Educación de la Universidad Nacional de La Plata, Agoglia acompaña la creación de la cátedra de "Historia del Pensamiento y Cultura Argentinos", iniciativa a la que se suman las facultades de Filosofía y Letras de la Universidad Nacional de Cuyo y de la Universidad de Buenos Aires (Roig 1993). En 1955 escribe "Alberdi y la filosofía de la historia", ensayo que, posiblemente debido a la censura impuesta por la autodenominada Revolución Libertadora, solo quedó registrado en formato de pruebas de galera ${ }^{3}$. Allí sostiene que "dentro de la moderna discusión filosófica acerca de la naturaleza de la historia, la teoría de Alberdi (...) corre paralela, en un sentido exclusivamente especulativo, a la solución hegeliana" (Agoglia 1955 13). Frente a la limitación metafísica a la que tiende el pensador alemán, sostiene que Alberdi, al identificar dialecticidad y temporalidad, propone una síntesis histórica. "Por eso no hay como en Hegel, un momento - aquél en que termina la realización histórica (...) - en que la razón humana vuelve autoconsciente todo el devenir temporal convirtiéndose en saber absoluto" (Agoglia 1955 22).

En la década del 70 vuelve sobre el pensamiento romántico y colabora con Arturo Roig en la publicación de la Biblioteca de pensamiento ecuatoriano. Centrado en el romanticismo del siglo XIX, se detiene en las ideas de León Mera, a quien describe como "un romántico que vive, percibe y asume el romanticismo como un americano, a través de un sentimiento y de una óptica propios" (Agoglia 1983a 279). Si bien identifica elementos antropológicos y literarios procedentes del Romanticismo alemán, subraya que Mera introduce una reformulación "desde sí mismo, desde su pueblo y desde su paisaje" (Ibíd.), cuando

3 Ese mismo año lo expulsan de la universidad, al igual que a Carlos Astrada, Luis Juan Guerrero y Miguel Angel Virasoro, entre otros. 
distingue, mediante la reivindicación de la politicidad inherente a las expresiones culturales, la afirmación de procesos sociales e históricos particulares del irracionalismo preponderante en la primera generación romántica europea.

En su primera etapa de producción filosófica en Argentina, entre las décadas del 50 y del 60, Agoglia indica que el racionalismo europeo de los siglos XVII y XVIII simpatiza con la concepción humanista de cultura legada por el Renacimiento, pero otorga a la razón científica el poder exclusivo de perfeccionar al hombre y sus producciones espirituales. En consecuencia, la pretensión de universalidad operante en la razón subjetiva conduce al desconocimiento o negación de las particularidades históricas. En reacción al Iluminismo, el Romanticismo concibe la naturaleza como producto "de fuerzas irracionales y orgánicas" que "se encauza y evoluciona no racional, sino vegetativamente, con ritmos inmodificables de crecimiento, maduración y muerte; y este origen y esta estructura impiden toda unidad y continuidad en el proceso" (Agoglia 1980b 60). En consecuencia, mientras el racionalismo provoca la deshumanización del hombre, de su singularidad y de su voluntad; el irracionalismo romántico impide pensar la praxis humana en términos de realidad histórica, limitándose a un conocimiento meramente descriptivo y externo del devenir histórico como mero transcurrir temporal o "historidad".

Agoglia afirma que Kant, en sus escritos metafísicos, contribuye a solucionar los dilemas abiertos por estas dos corrientes, en los que la relación entre el ser y el hombre delimita el campo de la metafísica como saber ontológico y circunscribe la praxis como objeto de la historia. Pero si Kant introduce una respuesta práctica, Hegel propone una solución teórica al problema de la historicidad humana desde la filosofía de la historia. El hombre es parte de la Naturaleza y del Espíritu, un ser atravesado por ambas dimensiones, condicionado por las circunstancias históricas, que se objetiva en la experiencia y en el conocimiento. La realidad histórica no es solo acontecer, sino también conciencia, instancia subjetiva y condición de posibilidad de la objetivación que, sin lograr asirla de manera absoluta, constituye la posibilidad de transformarla. De este modo, “(...) Hegel termina definiendo la historicidad (en sus dos formas, subjetiva y objetiva) como temporalidad consciente, y la realidad histórica como temporalidad objetiva a través 
de la cual se desarrolla el hombre merced a la conciencia histórica" (Agoglia 1980a 82).

Sin embargo, Agoglia encuentra que Hegel limita de forma unilateral el sentido de la Naturaleza a la racionalidad absoluta, y en los 60 avanza en dos dimensiones: por una parte, valora la comprensión nietzscheana de la historia como proyección del tiempo existencial; por otra, reflexiona sobre la síntesis teórico-práctica de los aportes del Iluminismo y del Romanticismo, operados por las luchas independentistas de los pueblos latinoamericanos del siglo XIX. En lo que se refiere a Nietzsche, complementa la orientación epistemológica de la denuncia de los modos tradicionales de hacer historia (anticuaria, monumental y crítica) con una ontología histórica. Al reconocer que el tiempo histórico es una proyección del tiempo existencial, encuentra en la experiencia ontológica de la historicidad - concepto que introduce Max Müeller en Expérience et histoire (1959) - el modo constitutivo de ser de lo histórico: lo dialéctico.

No solo el tiempo subjetivo determina las formas del conocimiento histórico en un nivel epistemológico, sino que el tiempo histórico (objetivo) condiciona nuestra experiencia subjetiva del devenir temporal. Agoglia observa que determinados acontecimientos "cruciales" en nuestra vida revelan una experiencia radical del acontecer temporal, pues repercuten no solo en la existencia individual, sino en el modo en que ocurre la historia. La conciencia de finitud de nuestra existencia, la "experiencia ontológica de la historicidad", nos impulsa a confiar en la continuidad de la historia como posibilidad de concreción efectiva de nuestros ideales y valoraciones (Agoglia 1968). En consecuencia, ante la experiencia de ruptura del tiempo histórico, advierte un impulso, una tendencia, que insta a un acto de reparación, de sanación de la continuidad del tiempo como afirmación sostenida en la esperanza de una efectiva transformación del presente.

Agoglia orienta la contribución marxista y existencialista poshegeliana al concepto moderno de historicidad, hacia una interpretación de la praxis de los movimientos sociales latinoamericanos. Frente a la solución dialéctica de Hegel, reconoce en las luchas independentistas de los pueblos latinoamericanos la trascendencia del plano meramente teórico a la dimensión política. Ante la estructura histórica de una totalidad cerrada y el sentido final de la historia universal, intuye la to- 
talidad histórica en la que acontecen los movimientos sociales. Crítico del sujeto moderno, advierte la racionalidad histórica del ser social y político, cuyo hacerse y gestarse se realiza efectivamente en comunidad. Del historicismo romántico latinoamericano rescata la dimensión política de la razón histórica en el proceso de realización de la libertad, pues en el siglo XIX:

(...) Cuando todas las Ciencias Sociales, fundadas en el Positivismo o Neo-positivismo, son instrumentos de esa dominación y la justifican u ocultan, los pueblos sojuzgados defienden históricamente su libertad y su personalidad y rechazan el concepto de civilización que nutre y sostiene el proceso de expansión colonial. Estos pueblos son los que sustituyen instintivamente el concepto de Civilización por el de Cultura Nacional que expresa ahora esa idea distinta de la originaria versión romántica y que trasciende también la intentada síntesis hegeliana, porque no solo reivindica la personalidad integral de los distintos pueblos (es decir espiritual tanto como política, social y económica), sino que engloba también en él la misma lucha por la independencia y la liberación social (Agoglia 1974 8).

En consecuencia, Rodolfo Agoglia realiza una interpretación del Romanticismo latinoamericano que toma distancia de la interpretación utilitarista de Alberini. Guiado por la lectura de Hegel, comprende que la generación del 37 no expresa el resultado de un Iluminismo en los fines y un historicismo en los medios. Distante de la caracterización de un historicismo instrumental, afirma que Alberdi asume la voluntad de emancipación legada por las ideas revolucionarias como medio para generar las instituciones necesarias que efectivicen nuestra emancipación del poder colonial. Ante la independencia política, formal, asume la necesidad de colaborar en una segunda emancipación, ideológica y cultural. Ante los "fundadores" de la Historia de las Ideas, cuestiona el academicismo operante en las cátedras de epistemología y, frente a la distinción entre saber teórico y saber vital, realiza una crítica del pensamiento filosófico europeo centrado en la realidad latinoamericana.

La crítica a la racionalidad científica asume la contribución de los filósofos poshegelianos y cuestiona la relación unilateral que subordina la naturaleza a la conciencia. De la experiencia existencial de finitud deduce la relación dialéctica entre tiempo y subjetividad, que le 
permite tomar distancia del colonialismo intelectual imperante en las universidades argentinas. La experiencia ontológica de la historicidad patentiza la estructura dialéctica que tensiona la vivencia radical de la finitud y el impulso que lleva a confiar en la continuidad del tiempo histórico como posibilidad efectiva de liberación.

\section{Hacia la formulación madura del historicismo como conciencia de una ruptura}

Si volvemos al panorama del historicismo latinoamericano, Roig indica un segundo momento a mediados de la década de los 60 , cuando "se produjo un importante fenómeno dentro de la historia intelectual y política latinoamericana (...) la constitución de la llamada 'Teoría de la dependencia"' (Roig 1993 96). La tensión universalidad-singularidad adquiere tenor en la polémica protagonizada por Augusto Salazar Bondy y Leopoldo Zea, en relación con la crítica marxista al problema de las ideologías. Adquiere nuevamente relevancia la pregunta formulada por Ardao en su lectura de Alberdi sobre "la naturaleza y el sentido de nuestra filosofía, el problema de la filosofía americana" (Ardao 63). Según Arpini, se inicia un periodo de crisis del historicismo, que tiene incidencia en el terreno de la Historia de las Ideas y deriva, a comienzos de los 70, en una etapa de reformulaciones.

En esta época, Roig ensaya una ampliación metodológica de la Historia de las Ideas que permita dar respuesta a la doble función del concepto: ideológica y crítica. Así, frente a la filosofía de la historia, propone trabajar en una "teoría crítica de la historia", que parta del reconocimiento de la historicidad de los discursos como reformulaciones de la conflictividad social. Su caracterización de la ambigüedad de la filosofía apunta a indicar la posición del sujeto inserto en la compleja y conflictiva realidad social. Dicho posicionamiento se materializa en la diversidad de movimientos, que dan cuenta de las alusiones, elusiones e ilusiones presentes en la enunciación discursiva, pudiendo derivar en una totalidad objetiva cerrada o, por el contrario, en una totalidad objetiva abierta con "conciencia de alteridad".

Por otra parte, la "reformulación del historicismo", dentro de la perspectiva dialéctica crítica propuesta por Agoglia, configura "una aproximación ontológica con método fenomenológico" a los caracteres ontológicos del ser de la realidad histórica. Este último, conformado 
por el tiempo histórico (objetivo) y la conciencia histórica (subjetiva), se constituye fundamentalmente por la "praxis social presentiva", compuesta de hechos y obras humanas producto de elecciones tomadas siempre en un presente conflictivo ${ }^{4}$ " "dialéctico" ${ }^{5}$. Como "totalidad estructurada" y "con sentido", todo suceso histórico, en tanto experiencia y conocimiento, emerge en relación con un conjunto de acontecimientos cuya estructura es "dinámica" 6 pero, contraria a la formulación metafísica hegeliana, orienta la acción humana en y con la praxis social.

Lejos de cerrar la problemática, la dilucidación de las categorías ontológicas de la historicidad conformada por tiempo y conciencia $-\mathrm{y}$ caracterizada como praxis social presentiva, dialéctica, dinámica, inserta en una totalidad estructurada y con sentido - postula, a modo de advertencia epistemológica, los peligros de deformar la historicidad (por desconocimiento o negación). Frente a Hegel y Dilthey, Agoglia critica los supuestos epistemológicos de la historia pasatista y la pretendida objetividad des-subjetivada del historiador. Por esto postula una epistemología de la historia que comprende las proyecciones del tiempo presente, pasado y futuro como "con-temporáneas". La actualización del tiempo histórico por el conocimiento parte de la experiencia subjetiva que se desplaza de la ilusión moderna de linealidad, progreso y objetividad. Atento a los ontologismos, reivindica el papel activo del historiador que, involucrado en su presente, indaga los otros presentes pasados. Ello no implica un mero subjetivismo, en tanto que, si bien el pasado es indagado siempre en relación dialéctica con el presente, el estudio del conocimiento histórico requiere de la construcción de categorías ontológicas mediante análisis empírico-sistemático, desde el cual distingue "nuestro presente de otros presentes ya pasados" bajo el

4 En este caso, el concepto de "historicidad" repercute también en el estudio de la historia, permitiendo al historiador abordar los hechos históricos desde el propio presente, a la vez que pone en tela de juicio la pretensión de objetividad de la filosofía de la historia tradicional.

5 En este sentido, aborda el problema de las mediaciones sociales, pues afirma que, dado "el carácter objetivo-subjetivo de la historicidad, como toda realidad humana", la historia en tanto experiencia y conocimiento nunca será objetiva en el sentido moderno (Agoglia 1980a 24).

6 Cabe resaltar que tal categoría implica ampliar los límites del estudio de hechos históricos, al tiempo que advierte que la totalidad estructurada se constituye en la historia, y no la historia a partir de ella, ya que esta última clausuraría la posibilidad de emergencia de lo nuevo. 
examen de nuestra experiencia en relación con otras manifestaciones culturales.

Desde estas precauciones metodológicas, Agoglia orienta la perspectiva historicista a la dimensión política de colaboración en la búsqueda y afirmación de nuestra identidad nacional. La tarea propuesta es descripta como una "indagación teórica (...) que tiene una insoslayable trascendencia práctica" (Agoglia 1983b 265), puesto que se constituye como "la conciencia de (...) una quiebra - por los consabidos factores políticos de la conquista y la colonización" (Ibíd.). Crítico de una visión esencialista del hombre latinoamericano, entiende que la situación histórica de dominación condiciona, pero no determina, la personalidad cultural de los pueblos. Pone en discusión, por errónea, la afirmación de una esencia de lo americano $\mathrm{y}$, contrario a los modos ontologistas de abordaje del problema de la identidad nacional, sostiene que, siendo la humanidad universal, sus modos de realización son históricos y peculiares. El error consiste en "trasladar ilegítimamente una noción metafísica al plano de la historia" (Id. 266).

En esta dirección, explora tres formas por las que se ha intentado dar una respuesta desde el seno de la intelectualidad a la idea de identidad nacional: la culturalista, en sus vertientes objetivista y subjetivista, la politicista y la historicista. A la primera la describe como "conciencia de una pérdida" que, en sus dos vertientes, nos consigna al pasado en la búsqueda de nuestra identidad materializada en diferentes expresiones culturales. En su orientación objetivista apunta al reconocimiento de "lo que efectivamente hemos hecho y hemos sido" y "lo que debemos seguir siendo"; en su versión subjetivista busca dilucidar "al hombre profundo, que se encamina al pueblo interior, al fondo y al principio originarios sin los cuales las nacionalidades se disgregarían" (Agoglia 1983b 267). En segundo lugar, describe la corriente politicista representada por los "movimientos populistas y socialdemócratas latinoamericanos" (Ibíd.) como "conciencia de una solución" que se sostiene en el presente como lugar de la praxis. Por último, desde la expresión historicista entendida como "conciencia de una ruptura", afirma que la identidad nacional "está condicionada en Latinoamérica por la conciencia y la efectivización de nuestra liberación política y ésta por el desarrollo de una conciencia histórica que se va constitu- 
yendo progresivamente a través de la tensión dialéctica entre futuro y presente" (Id. 268).

De modo que, si para el culturalismo la reconstrucción de la identidad nacional consiste en el rescate de las diferentes manifestaciones culturales y para el politicismo radica en la construcción de una estructura "que garantice nuestra liberación", para el historicismo la personalidad histórica quebrada es "recuperable e integrable" por nuestra historicidad (Agoglia 1983b 268). La interpretación de Agoglia apunta en primer lugar contra el culturalismo, en el que observa el predominio de una idea de "personalidad cultural" polémica y peligrosa, que podría quedar limitada a un academicismo o, peor aún, a un ontologismo:

Llevado por el legítimo afán de rescate y consolidación de lo propio - que nos ha sido arrebatado o conculcado- se ve insensiblemente arrastrado a un espontaneísmo y a un individualismo histórico tan enfáticos que arriesga derivar en un optimismo ilusorio y en un fatalismo engañoso consistentes en creer que dejando ser a los pueblos, dejando actuar a fuerzas espontáneas no racionales ellas habrán de realizarnos culturalmente (Agoglia 1983b 269).

La falaz oposición del culturalismo subjetivista entre las "culturas tradicionales" u "autóctonas", estimadas como "profundamente humanistas", y las "culturas importadas de Occidente", caracterizadas como "económicas, materialistas y eminentemente tecnológicas, es proclive al irracionalismo o intuicionismo en su declarado "anti-economicismo y (...) antirracionalismo científico-tecnológico" (Id. 268). El conflicto se agudiza en la afirmación de las culturas nacionales mediante una "rebelión romántica (...) ante el avance incontenible de las culturas occidentales 'alienantes' y 'destructivas' de los pueblos política o económicamente dependientes" (Ibíd.). Por este motivo, advierte que la vertiente objetivista es más moderada, ya que se apoya en el supuesto antropológico de la capacidad de construirnos culturalmente.

En esta dirección, Agoglia dirige tres críticas a las expresiones culturalistas. Primero, cuestiona la interpretación que liga el conocimiento de lo que somos a nuestra praxis política, en la que se afirma que "nos urge (...) el conocimiento y la restitución de aquello de lo que fuimos despojados" (Agoglia 1983b 270). Aquí advierte que la limitación de la praxis al conocimiento del pasado, con más razón cuando esta 
pretende, en su vertiente subjetivista, un regreso ahistórico a un pasado originario, puede intencionalmente o no olvidar el señalamiento de las "carencias objetivas", porque "son estructuras reales (sociales y políticas) las que cierran el camino a nuestras posibilidades" (Ibíd.). En segundo lugar, afirma que, antes que una razón autorreflexiva, es indispensable una "razón observante y operante, capaz de remover esas trabas y obstáculos exteriores" (Ibíd.). Cuestiona la tendencia culturalista a buscar formas de "justificarnos a nosotros mismos, de mostrar y demostrar nuestra humanidad", porque observa que esta tarea nos ha sido impuesta ideológicamente "para convalidar la conquista y la colonización" (Ibíd.). En contestación a Zea, sostiene que no es la crisis de Europa la que nos ofrece la oportunidad "de afirmar la humanidad de América Latina", porque ello implica asumir "una premisa ideológica y cohonestarla". No necesitamos justificación de nuestra humanidad, sino "apoderarnos de nuestra realidad y compenetrarnos con la naturaleza, el mundo y el tiempo en que vivimos (Id. 271). Por último, advierte que el culturalismo es propenso a olvidar la necesidad práctica de la indagación teórica sobre la identidad nacional, ya que, si las naciones no son "núcleos originarios y específicos", ni esencias a desarrollarse en la historia, la liberación política no es la consecuencia sino "la condición de posibilidad de una cultura nacional" (Ibíd.). Por esta razón, la relación entre nacionalismo cultural y nacionalismo político es propensa a asumir un "nacionalismo ideológico, que no busca esencialmente una liberación sino con intención encubierta, el afianzamiento del Estado y las instituciones en cuanto responden a los intereses de los grupos y factores sociales de poder" (Ibíd.).

En referencia al politicismo, Agoglia realiza una autocrítica de los gobiernos populistas en América Latina, a los cuales define como:

(...) democracias de masa que, además de afirmar prioritaria e incondicionalmente la soberanía política, en lo social han invocado al pueblo, sin idealizarlo y sin distinción de clases, para promover transformaciones que en la mayoría de las circunstancias quedaron limitadas a sustanciales mejoras y beneficios para los sectores más desposeídos, y en lo económico, han buscado una síntesis nunca lograda entre una distribución social de la riqueza y un capitalismo nacional. Doctrinariamente fueron, en lo político, ensayos de social-democracia independientes, en algunos casos anteriores, 
y más sólidos que la democracia social europea; y a diferencia de ésta no intentaron nunca alianzas con el liberalismo, aunque si, en casi todos los órdenes, una integración y, las más de las veces, una conciliación entre tendencias antagónicas (Agoglia 1983b 272).

La expresión populista del politicismo es un fenómeno complejo que difiere de las críticas economicistas, aun de las procedentes del marxismo, que desconocen o niegan la singularidad de los procesos políticos latinoamericanos. Si observamos los aportes de las teorías de la dependencia, fundamentalmente la crítica al feudalismo interno y a la perspectiva desarrollista, la reflexión de Agoglia indica que la "total emancipación y autodeterminación políticas" no implican tareas conclusivas, sino el punto de partida para "promover también cambios socio-económicos estructurales que apuntalen la sustancia política liberada" (Agoglia 1983b 273). No se desliga del factor socioeconómico, sino que, para evitar un economicismo desligado de la realidad histórica, comprende como prioridad "la institucionalización jurídica, social y económica” de las conquistas políticas (Ibíd.). Sin embargo, sostiene que el politicismo es insuficiente si se reduce a "llenar un determinado vacío práctico", porque si bien "él nos plantea una tarea presente y nos insta a la acción", estas "sólo tendrán sentido y no estarán signadas de antemano al fracaso, si se cumplen con una lúcida y coordinante conciencia histórica" (Id. 274).

Por esta razón, avanza finalmente en la caracterización del historicismo como integración de las diferentes proyecciones del tiempo histórico. Si el futuro no es concebido como "emergente" del presente, ni como desarrollo del pasado, sino como alteridad que orienta "nuestra emancipación actual y la salvación de nuestro pasado", se disuelve la noción lineal del tiempo que contempla al presente como "término de un proceso" y "restauración del pasado". Un futuro "que se inserta diacrónicamente en el decurso del tiempo" tiene la potencia que puede liberar el presente de su mera facticidad y al pasado de la simple repetición:

El historicismo se opone por igual a un culturalismo y un politicismo unilaterales, pues el primero invoca la conciencia de una pérdi$d a$, el segundo alega la conciencia de una solución, mientras que el historicismo tiene conciencia de una ruptura. La pérdida es siempre irreparable, y la solución aparece siempre como definitiva. Es como 
si para el culturalismo lo último fuera el pasado, y para el politicismo lo último fuera el presente. Pero el tiempo no se consuma ni en el uno ni en el otro. Porque si lo perdido está, como tal, perdido irremisiblemente, ofrece, pese a ello, la ocasión de tomar conciencia de la capacidad de recuperarnos, no por restauración, sino por el restablecimiento de la continuidad de nuestro tiempo. Reactualizar no es restaurar, sino re-poner (en otra instancia y otro contexto, y con otra connotación y otra función) lo que puede conectar con nuestra situación presente; es otorgarle al pasado una nueva significación para otro momento del tiempo, el presente nuestro, permitiendo así la realización diacrónicamente coordinada de lo que aspiramos o queremos llegar a ser (Agoglia 1983b 275).

Si "la pérdida es siempre irreparable", Agoglia señala que es posible "reponer el pasado", actualizarlo e integrarlo al presente y al futuro a fin de "subsanar la ruptura del tiempo" (Id. 276). Si el politicismo postula la praxis como "modelos terminales de racionalidad", es necesario advertir que "por encima" de ellos, "está la racionalidad del fin que, como miembros de una comunidad humana nacional, perseguimos, y que no puede ser otro que una liberación integral" (Ibíd.). Desde el historicismo, pasado y presente constituyen "momentos de una permanente realización del hombre en su 'mundo propio', vertebrada por la integración del tiempo histórico" (Ibíd.).

El ser de la historia radica para Agoglia en la historicidad. Atento a la conciencia de la alteridad, no limita la historicidad al pasado, ni la reduce a lo cuantitativamente nuevo, sino que realiza una apertura desde el estudio diacrónico y sincrónico del tiempo histórico. Crítico del fin último, deshistorizante, no deja de confiar en que el hombre despliega en la historia sus posibilidades, pero también encuentra resistencias. Desde una reformulación de los alcances de la racionalidad histórica, asume una posición crítica frente a los excesos de la razón científica. A diferencia del circunstancialismo, el concepto de "historicidad" operante en sus reflexiones teórico-metodológicas cuestiona no solo la interpretación lineal del texto y de las producciones culturales, sino también la linealidad y el progreso proyectados por nuestra conciencia temporal. Su denuncia al culturalismo es antecedida por la crítica a la cultura filosófica universitaria que legitima la dominación a través de las diferentes formas de academicismo. Pues sostiene que la 
función de la filosofía es colaborar con la liberación política favorable a la formación de una conciencia nacional crítica del imperialismo.

\section{A modo de síntesis}

Las primeras tesis de Rodolfo Agoglia, configuradas entre los años 40 y 50, toman como punto de partida los debates sobre la historicidad desde los instrumentos teóricos procedentes de las relecturas de los filósofos románticos europeos y latinoamericanos del siglo XIX, en tensión con las herramientas procedentes de la fenomenología y las filosofías de la existencia. Continúa la tarea iniciada por Coriolano Alberini y reformulada por Luis Juan Guerrero y Carlos Astrada. Profundiza en la perspectiva política sostenida por los pensadores más afines al peronismo y, crítico de las apropiaciones de Dilthey y Ortega y Gasset, cuestiona la pretensión de neutralidad valorativa y las diferentes formas de academicismo. Desde el legado de las ideas románticas argentinas dirige su crítica al colonialismo intelectual y a las pretensiones aristocráticas de patriotismo.

La reflexión sobre el concepto de "conciencia histórica" toma relativa distancia de la filosofía de la historia hegeliana y, si bien asume lo más fecundo del filósofo alemán, tensiona sus elementos críticos con la contribución de la generación romántica latinoamericana. En alusión a las filosofías que han legitimado y/u ocultado la relación de dependencia de nuestros países, como así también a las filosofías academicistas que menosprecian, en su pretensión de objetividad, la necesidad acuciante de pensar nuestros problemas políticos, sociales y económicos desde la Conquista cuestiona la negación o reconocimiento defectivo de la historicidad como recurso ideológico para legitimar a nivel discursivo la dominación.

La formulación madura del historicismo, entendido como conciencia de una ruptura, avanza en una integración dialéctica del tiempo histórico que tiene como objetivo la curación del tiempo. Esta posibilidad de reparación se asienta en una crítica a los límites del culturalismo y del politicismo, desde una experiencia de la temporalidad cualitativamente otra, que pone en crisis las pretensiones de totalidad, pero que no renuncia a la racionalidad histórica. Ante la ilusión de un presente que se presenta como mera facticidad, y de un pasado que amenaza con repetirse, el futuro inyecta en el presente la concien- 
cia de la posibilidad efectiva de una racionalidad transformadora. La "conciencia de una ruptura" asume la doble arista teórico/práctica que acompaña el proceso de liberación mediante la contribución de una razón operante que lee en las condiciones históricas presentes la persistencia de la colonización. No obstante, avanza en la proyección de un futuro cualitativamente otro, alternativo, que procura la integración de una historicidad rota que obstaculiza, pero no determina la efectiva posibilidad de emancipación.

\section{Bibliografía}

Agoglia, Rodolfo. "Alberdi y la filosofía de la historia". S/L: S/E, 1955.

Agoglia, Rodolfo. "Perspectivas de la razón histórica", Cuadernos de Filosofía 10 (1968): 289-311.

Agoglia, Rodolfo (1974). "Cultura Nacional” Disertación en la Universidad Nacional de La Plata en el acto de inicio del Curso de Perfeccionamiento Docente. Versión taquigráfica. La Plata, Secretaría de Prensa y Difusión, Departamento de Informaciones y Prensa, Universidad Nacional de La Plata. 14 pp. Disponible en línea: https://es.scribd.com/doc/267976633/ Agoglia-Rodolfo-Disertacion-Sobre-Cultura-NacionalUnlp-1974

Agoglia, Rodolfo. Conciencia histórica y tiempo histórico. Ecuador: Pontifica Universidad Católica del Ecuador, 1980a.

Agoglia, Rodolfo. Pensamiento romántico ecuatoriano. Ecuador: Banco Central del Ecuador, 1980.

Agoglia, Rodolfo. "Juan León Mera exponente típico del romanticismo ecuatoriano", Cuadernos Salmantinos de filosofía 10 (1983a): 279-282.

Agoglia, Rodolfo. "La idea de identidad nacional en América Latina", Cuadernos Salmantinos de filosofía 10 (1983b): 265-278.

Agoglia, Rodolfo "La relación hombre-naturaleza en el pensamiento actual". Diario El Comercio. Suplemento Cultural, Domingo 6 de marzo de 1983: 6-7.

Alberini, Coriolano. La patria en la universidad. Buenos Aires: Universidad de Buenos Aires, 1941.

Ardao, Arturo. "El historicismo y la filosofía americana". La filosofía de la lengua española. Ensayos. 1946. Montevideo: Editorial Alfa, 1963. 63-72. 
Arpini, Adriana. Otros discursos. Estudios de historia de las ideas latinoamericanas. Mendoza: Facultad de Ciencias Políticas y Sociales/UN Cuyo, 2003.

Biagini, Hugo. "Autohistoria sumaria de las ideas", Pacarina del Sur [En línea], 6/23 (2015). Disponible en línea: http//:

www.pacarinadelsur.comindex.php?option=com content\&view=artic le\&id=1133\&catid=4\&Itemid

Cerutti, Horacio. Hacia una metodología de las ideas (filosóficas) en América Latina. México: Universidad de Guadalajara, 1986.

Cerutti, Horacio. Filosofía de la liberación latinoamericana. México: Fondo de Cultura Económica, 2006.

Friz Echeverría, Cristóbal. "Revisitando la discusión entre Augusto Salazar Bondy y Leopoldo Zea. La filosofía latinoamericana: El lugar de un diferendo", Revista de filosofía 76 (2019): 57-74.

Ibarlucía, Ricardo. "Luis Juan Guerrero: La conciencia histórica en el siglo XVIII. Edición crítica, introducción y notas", Páginas de filosofía 19/22 (2018): 100-109.

Oviedo, Gerardo. "Historia autóctona de las ideas filosóficas y autonomismo intelectual: sobre la herencia argentina del siglo XX", La Biblioteca 2-3 (2005): 76-98.

Pérez Zavala, Carlos. La filosofía latinoamericana como compromiso. Río Cuarto: Ediciones del ICALA, 2005.

Roig, Arturo. "El concepto de 'Historia de las ideas' en Coriolano Alberini”, Cuyo 4 (1968): 147-157

Roig, Arturo. "Problemática de la filosofía latinoamericana". Filosofía, universidad y filósofos en América Latina. 1978. México: Universidad Nacional Autónoma de México, 1981. 73- 90.

Roig, Arturo. “Tres décadas de 'Historia de las ideas' en Argentina: recuento y balance". Historia de las ideas, teoría del discurso y pensamiento latinoamericano. Colombia: Universidad de Santo Tomás, 1993. 91-104.

Roig, Arturo. Teoría y crítica del pensamiento latinoamericano. Buenos Aires: Una ventana, 2009.

Roig, Arturo. Metodología y filosofía del pensamiento latinoamericano. Compilado por: Carlos Paladines. Ecuador: Academia Nacional de Historia, 2013.

Romero, Francisco. "La filosofía en Iberoamérica". Filosofía de la persona y otros ensayos de filosofía. Buenos Aires: Losada, 1961. 
Velarde Cañazares, Marcelo. Alteridad y existencialismo en la Argenti$n a$. Tesis de doctorado en Filosofía en co-tutela. Universidad Nacional de Lanús y Université Paris 8 Vincennes - SaintDenis, 2011. 